\title{
Risk Factors for Early Discontinuation of Breastfeeding in Iranian Mothers
}

\author{
Fatemeh Ghotbi ${ }^{1}$, Ali Naseh ${ }^{2}$, Eznollah Azargashb ${ }^{3}$, Shahrbano Hajimola Ahmad Naraghi ${ }^{4}$, \\ Azadeh Akbari Sene ${ }^{*}$
}

\begin{abstract}
${ }^{1}$ Infertility and Reproductive Health Research Center (IRHRC), Shahid Beheshti University of Medical Sciences, Tehran, Iran ${ }^{2}$ Neonatal Intensive Care Unit, Taleghani Hospital, Shahid Beheshti University of Medical Sciences, Tehran, Iran

${ }^{3}$ Department of Social Medicine, Shahid Beheshti University of Medical Sciences, Tehran, Iran

${ }^{4}$ Department of Obstetrics and Gynecology, Taleghani Hospital, Shahid Beheshti University of Medical Sciences, Tehran, Iran ${ }^{5}$ OBGYN/IVF Fellowship, Iran University of Medical Sciences, Shahid Akbar-Abadi Hospital IVF Center, Tehran, Iran

Email:*doctor_asturias@yahoo.com
\end{abstract}

How to cite this paper: Ghotbi, F., Naseh, A., Azargashb, E., Naraghi, S.H.A. and Sene, A.A. (2016) Risk Factors for Early Discontinuation of Breastfeeding in Iranian Mothers. Open Journal of Obstetrics and Gynecology, 6, 606-614.

http://dx.doi.org/10.4236/ojog.2016.610076

Received: August 12, 2016

Accepted: September 16, 2016

Published: September 19, 2016

Copyright $\odot 2016$ by authors and Scientific Research Publishing Inc. This work is licensed under the Creative Commons Attribution International License (CC BY 4.0).

http://creativecommons.org/licenses/by/4.0/ (c) (†) Open Access

\begin{abstract}
Objective: The present study was conducted to evaluate the risk factors that reduce the rate of breastfeeding among Iranian women in the first six months after delivery. Materials and Methods: This cross sectional study was performed on 542 mothers with infants less than six months old who came to Taleghani Hospital, Tehran, Iran, for vaccination follow up, from 2012 to 2014. Trained examiners filled a predesigned questionnaire including information about breastfeeding and factors that may affect the mode of infant feeding. The results were analyzed using SPSS software. Results: Out of 542 breastfeeding infants $53.2 \%$ were female; the average birth weight was $3217 \pm 40$ gr and $57.7 \%$ were first born. The age of mothers was from 17 to 43 years with the average of $27.7 \pm 4.9$. Among mothers $58.1 \%$ had a high school diploma or less education and $41.9 \%$ had higher education. The rate of cesarean section was $62.2 \%$. The rate of breastfeeding showed a reducing trend from the first month after birth to the sixth month: $91.7 \%$ of mothers reported breastfeeding in the first month which was reduced to $70.1 \%$ in the sixth month. Multivariate analysis using logistic regression analysis showed the risk factors reducing the rate of breastfeeding as follow: use of pacifier $\left(\mathrm{P}<0.000, \mathrm{OR}=3.695, \mathrm{CI}_{95 \%}=2.460-5.553\right)$, cesarean section delivery $\left(\mathrm{p}<0.000, \mathrm{OR}=2.717, \mathrm{CI}_{95 \%}=1.690-4.369\right)$, lack of breastfeeding training $\left(\mathrm{P}=0.004, \mathrm{OR}=2.347, \mathrm{CI}_{95 \%}=1.354-4.063\right)$, and mothers' higher education $(\mathrm{P}=$ $\left.0.029, \mathrm{OR}=1.614, \mathrm{CI}_{95 \%}=1.014-2.569\right)$. Conclusion: Use of pacifiers, cesarean section, lack of breastfeeding training, and mothers' higher education were the risk factors for reduced breastfeeding among Iranian mothers.
\end{abstract}




\section{Keywords}

Infant, Breastfeeding, Pacifier, Risk Factor, Cesarean Section

\section{Introduction}

There are many studies emphasizing the importance of breastfeeding in childhood.

Based on World Health Organization instructions exclusive breastfeeding, meaning feeding the infant only with mothers' own milk without adding anything or using other forms of milk except for vitamins should be performed at least up to sixth months after birth [1].

Mothers' milk includes different factors which improves the immune system of the infants [2]. Breastfeeding prevents the death of 1.4 million children under five years old in developed countries by reducing the rate of respiratory and gastrointestinal infections among infants [3] [4].

Breastfeeding is influenced by several factors including the financial and psychosocial characteristics of the family, health care practices, social support, and the attitude of the society towards breastfeeding [5] [6]. In the Middle East duration of breastfeeding has shown a relation with the age of mothers [7]-[10], and the number of children [8] [11] [12], so mothers with higher age and experience of previous child bearing show a higher rate of breastfeeding.

In other studies the education level of mothers has shown negative [10] [13] [14], or positive [11] relations with breastfeeding. A negative influence on breastfeeding and the use of pacifiers has been revealed in different studies [15] [16], introducing pacifiers in the early months has been observed to have a bigger negative influence than starting pacifier use after the first months [17].

We conducted the present study to evaluate the risk factors that reduce the rate of breastfeeding among Iranian women in the first six months of their infant's life.

\section{Materials and Methods}

This cross sectional study was performed on 542 mothers with infants less than six months old who came to Taleghani Hospital, Tehran, Iran, for vaccination follow up from 2012 to 2014. Trained examiners filled a pre-designed questionnaire including the information related to breastfeeding and relevant factors. The questionnaire was adopted from a previous study assessing the breastfeeding risk factors conducted in Kuwait [18].

The questionnaire included questions assessing the demographic of the family, personal characteristics of the mother and the infant, the method of breastfeeding. The inclusion criteria were being a healthy infant with a delivery weight of above 2500 gr and delivery no earlier than $37^{\text {th }}$ week. All mothers including in this study had positive attitude towards breastfeeding after delivery. Exclusion criteria were any chronic disease or congenital malformations influencing the breastfeeding, being twins, the infant stay in 
the hospital of more than two days after delivery, maternal medical conditions that may interfere with breastfeeding or lead to long maternal hospitalization, and taking any medication which is contraindicated during lactation. The results were analyzed using SPSS version software 16 (SPSS Inc., Chicago IL). We used Chi square, Fisher's exact test and logistic regression methods to analyze the data and $\mathrm{p}$ values less than 0.05 were considered statistically significant.

The sample size calculation was based on previous studies to assess the risk factors with a $95 \%$ confidence and was 521 samples. We entered 542 samples in our study. The principles of the Helsinki Declaration were followed in this study and all subjects provided written informed consent with guarantees of confidentiality.

\section{Results}

The mean maternal age of our studied population was $27.74 \pm 4.9$ years old and $57.7 \%$ of the subjects were primiparous. $58.1 \%$ of these mothers did not have university education and $68.1 \%$ were house wives. The demographic findings of infants and mothers are highlighted in Table 1 . Table 2 shows the percentage of breastfeeding in different months after delivery. In total 337 infants (62.2\%) were delivered using cesarean section and 205 infants (37.8\%) were born by vaginal delivery. The method of delivery had a statistically significant influence on breastfeeding with those infants delivered by cesarean section showing less breastfeeding $(\mathrm{p}<0.001)$ (Table 3$)$.

Education level of mothers did not show a significant influence on breastfeeding in the first two months but there was a significant relation in months $3(\mathrm{p}=0.044), 4$ ( $\mathrm{p}=$ 0.008), 5 ( $\mathrm{p}<0.001)$ and 6 ( $\mathrm{p}<0.001)$, showing less breastfeeding among mothers with higher education, compared to those with high school diploma or less education.

Out of 542 mothers 369 mothers (68.1\%) were housewives and 172 mothers (37.1\%)

Table 1. Infants gender, parity, and maternal demographics.

\begin{tabular}{cc} 
Infant sex (n, \%): & \\
female & $289(53.3)$ \\
male & $253(46.7)$ \\
Parity (n, \%): & \\
$\qquad 1^{\text {st }}$ & $313(57.7)$ \\
$>1^{\text {st }}$ & $229(42.3)$ \\
Mother education (n, \%): & $315(58.1)$ \\
High school or less & $227(41.9)$ \\
university & \\
Employment status (n, \%): & $369(68.1)$ \\
House wife & $172(31.7)$ \\
Employed & $27.74 \pm 4.9,17-43$ \\
\hline Mothers' ageing years (mean \pm SD, range)
\end{tabular}


were employed with a six months child maternity leave. As shown in Table 4 there was not a significant relationship between mothers being employed and the rate of breastfeeding in the first to forth month after delivery, but this relation was statistically significant in the months 5 and 6 showing less chance of breastfeeding among employed mothers. This total difference was not significant in multivariate analysis.

Out of 542 mothers 463 mothers $(85.4 \%)$ had breastfeeding training. Those without training showed significantly less breastfeeding in the first two months after delivery $(\mathrm{p}<$ $0.001)$.

There was a statistically significant difference between those infants using pacifiers and those not using pacifiers in all months after delivery except for the first month (Table 5).

Multivariate analysis using logistic regression analysis showed the risk factors reducing

Table 2. Feeding pattern in the first 6 months after delivery.

\begin{tabular}{cccc}
\hline Month & Breast Milk n (\%) & Formula n (\%) & Breast milk + Formula n (\%) \\
\hline $1^{\text {st }}$ & $497(91.7)$ & $15(2.8)$ & $30(5.5)$ \\
$2^{\text {th }}$ & $475(87.6)$ & $26(4.8)$ & $41(7.6)$ \\
$3^{\text {th }}$ & $440(81.2)$ & $36(6.64)$ & $66(12)$ \\
$4^{\text {th }}$ & $425(78.4)$ & $44(8.1)$ & $73(13.5)$ \\
$5^{\text {th }}$ & $387(71.4)$ & $56(10.3)$ & $99(18.2)$ \\
$6^{\text {th }}$ & $380(70.1)$ & $59(10.9)$ & $103(19)$ \\
\hline
\end{tabular}

Table 3. The effect of cesarean delivery on breast feeding at first 6 months after delivery.

\begin{tabular}{cccccc}
\hline Infant age (month) & Cesarean section $\mathrm{n}(\%)$ & Vaginal delivery $\mathrm{n}(\%)$ & Odds Ratio & $\mathrm{CI}_{95 \%}$ & P-value \\
\hline 1 & $302(89.6)$ & $195(95.1)$ & 2.260 & $1.094-4.668$ & 0.025 \\
2 & $284(84.3)$ & $191(93.2)$ & 2.546 & $1.374-4.718$ & 0.002 \\
3 & $254(75.8)$ & $186(90.7)$ & 3.122 & $1.83-5.326$ & 0.000 \\
4 & $240(71.2)$ & $185(90.2)$ & 3.739 & $2.227-6.277$ & 0.000 \\
5 & $214(63.5)$ & $173(84.8)$ & 3.208 & $2.062-4.99$ & 0.000 \\
6 & $207(61.4)$ & $173(84.8)$ & 3.395 & $2.195-5.252$ & 0.000 \\
\hline
\end{tabular}

Table 4. The effect of employment on breast feeding.

\begin{tabular}{cccccc}
\hline Age (months) & House wives n (\%) & Employed n (\%) & Odds Ratio & CI95\% & P-value \\
\hline 1 & $340(92.1)$ & $156(90.7)$ & 1.202 & $0.625-2.278$ & 0.617 \\
2 & $320(86.7)$ & $154(89.5)$ & 0.763 & $0.430-1.354$ & 0.402 \\
3 & $308(83.7)$ & $132(77.2)$ & 1.517 & $0.965-2.383$ & 0.074 \\
4 & $298(80.8)$ & $127(73.8)$ & 1.487 & $0.970-2.280$ & 0.073 \\
5 & $277(75.3)$ & $110(64)$ & 1.716 & $1.160-2.537$ & 0.008 \\
6 & $270(73.2)$ & $110(64)$ & 1.537 & $1.044-2.264$ & 0.034 \\
\hline
\end{tabular}


Table 5. Pattern of breastfeeding during $1^{\text {st }}$ six months in pacifier and non-pacifier users.

\begin{tabular}{ccccc}
\hline Age (months) & Pacifier users n (\%) & Non-pacifier users n (\%) & Total & P value \\
\hline 1 & $176(88)$ & $321(93.9)$ & 497 & 0.051 \\
2 & $163(81.5)$ & $312(91.2)$ & 475 & 0.003 \\
3 & $141(70.9)$ & $300(87.7)$ & 441 & 0.000 \\
4 & $130(65)$ & $295(86.3)$ & 425 & 0.000 \\
5 & $110(55)$ & $277(81.2)$ & 387 & 0.000 \\
6 & $104(52)$ & $276(80.7)$ & 380 & 0.000 \\
\hline
\end{tabular}

the rate of breastfeeding as follow: use of pacifier $\left(\mathrm{P}<0.001, \mathrm{OR}=3.695, \mathrm{CI}_{95 \%}=2.460\right.$ 5.553), cesarean section delivery ( $\left.\mathrm{p}<0.001, \mathrm{OR}=2.717, \mathrm{CI}_{95 \%}=1.690-4.369\right)$, lack of breastfeeding training $\left(\mathrm{P}=0.004, \mathrm{OR}=2.347, \mathrm{CI}_{95 \%}=1.354-4.063\right)$, and higher mothers' education $\left(\mathrm{P}=0.029, \mathrm{OR}=1.614, \mathrm{CI}_{95 \%}=1.014-2.569\right)$.

\section{Discussion}

In the present study 91.7 percent of mothers were breastfeeding in the first month after delivery which steadily reduced in later months. Similar studies have indicated a similar pattern of decline in the rate of breastfeeding in later months after delivery [19]-[22]. The rate of breastfeeding has been reported to be $83 \%$ in Tehran, Iran, $70 \%$ in Italy, $37 \%$ in Alberta (Canada), and 23\% in Ontario (Canada) [19]-[21].

The early termination of breastfeeding or a reduction of breastfeeding is related to different infant and maternal factors. Maternal factors include mothers' age, mothers' level of education, employment, number of children, health condition, multiple gestation, mode of delivery and the mothers' attitude toward breastfeeding [10] [19] [21] [23]. Some other risk factors are nipple pain and inappropriate latch during breastfeeding [22].

In the present study the number of children was not related to the rate of breastfeeding. Also the mother being employed showed a negative impact on breastfeeding only in the fifth and sixth months which might be due to mothers returning to work in later months thus reducing the chance of continued breastfeeding.

We found higher level of education among mothers to be a risk factor reducing the rate of breastfeeding. Shiva et al. [21], showed that mothers' level of education did not have any influence on the rate of breastfeeding, but some other studies have indicated a negative [10] [13] [14], or positive impact of higher education on breastfeeding [19] [20] [24].

Cesarean section has been shown to be a risk factor reducing the rate of breastfeeding similar to our findings [25] [26].

In recent decade several studies have been carried out studying the impact of using pacifiers in breastfeeding some of them indicating the use of pacifiers as a risk factor reducing the rate of breastfeeding [27]-[30]. Some other studies did not find a statistically significant relationship between the use of pacifiers and the rate of breastfeeding 
[21] [30]-[33]. In the present study the use of pacifiers showed a negative impact on the rate of breastfeeding in the first six months after delivery. Three other studies from Iran have shown similar results [34]-[36]. Mauch et al. [17], after studying 670 Australian primipara mothers showed a statistically significant difference in rate of breastfeeding among infants starting the use of pacifiers in the first month after delivery and those infants who never used pacifiers [17]. Gerd et al. [37], in Sweden showed a negative impact on breastfeeding after use of pacifiers. A similar result has been found in studies from Brazil and Spain [28] [38]-[40]. In a recent study the limited use of pacifiers was compared to unlimited use, which did not show a difference regarding its impact on breastfeeding [30]. In another study on 1021 full term infants from Argentina, from mothers interested in full breastfeeding who started the use of pacifiers at least 15 days after the start of breastfeeding, no statistically significant relation to the rate of breastfeeding were established [32]. Jaafar et al. [29], in a meta-analysis of previous studies on the impact of using pacifiers on breastfeeding indicated that the use of pacifiers reduces the rate of exclusive breastfeeding in univariate and also multivariate analysis. Also there was a higher risk of complete breastfeeding termination among infants using pacifiers.

As our main limitation, this was a cross sectional study. Further RCTs with larger study populations would enhance our understanding about the risk factors that may interfere with successful inclusive breastfeeding.

As a conclusion, based on data of this research, use of pacifier, cesarean section, lack of breastfeeding training, and mothers' higher education were the risk factors for reduced breastfeeding among Iranian mothers.

\section{Acknowledgements}

We would like to highly express our gratitude towards Dr Kourosh Sheibani for his invaluable help on preparing this article.

\section{Conflict of Interest}

Authors declare that they have no conflict of interest with the subject matter of this manuscript.

\section{References}

[1] WHO (2003) Global Strategy for Infant and Young Child Feeding. WHO, Geneva. http://www.who.int/nutrition/publications/infantfeeding/9241562218/en/

[2] Labbok, M., Clark, D. and Goldman, A. (2004) Breast Feeding Maintaining an Irreplaceable Immunological Resource. Nature Reviews Immunology, 4, 565-572.

[3] UNICEF (2008) Infant and Young Child Feeding. http://www.unicef.org/nutrition/index breastfeeding.html

[4] UNICEF (2004) Global Strategy: Breastfeeding Critical for Child Survival. http://www.who.int/mediacentre/news/releases/2004/pr19/en/

[5] Yngve, A. and Sjostrom, M. (2001) Breastfeeding Determinants and a Suggested Framework for Action in Europe. Public Health Nutrition, 4, 729-739. 
http://dx.doi.org/10.1079/PHN2001164

[6] Scott, J. and Binns, C. (1999) Factors Associated with the Initiation and Duration of Breastfeeding: A Review of the Literature. Breastfeed Review, 7, 5-16.

[7] Khattab, M.S. (2000) Cross-Sectional Study of a Child Health Care Program at One Family Practice Centre in Saudi Arabia. Eastern Mediterranean Health Journal, 6, 246-259.

[8] Batal, M., Boulghourjian, C., Abdallah, A. and Afifi, R. (2006) Breast-Feeding and Feeding Practices of Infants in a Developing Country: A National Survey in Lebanon. Public Health Nutr., 9, 313-319. http://dx.doi.org/10.1079/PHN2006860

[9] Osman, N. and El-Sabban, F.F. (1999) Infant-Feeding practices in Al-Ain, United Arab Emirates. Eastern Mediterranean Health Journal, 5, 103-110.

[10] Radwan, H. (2013) Patterns and Determinants of Breastfeeding and Complementary Feeding Practices of Emirati Mothers in the United Arab Emirates. BMC Public Health, 13, 171. http://dx.doi.org/10.1186/1471-2458-13-171

[11] Hajian-Tilaki, K.O. (2005) Factors Associated with the Pattern of Breastfeeding in the North of Iran. Annals of Human Biology, 32, 702-713. http://dx.doi.org/10.1080/03014460500272764

[12] Al-Sahab, B., Tamim, H., Mumtaz, G., Khawaja, M., Khogali, M., Afifi, R., et al. (2008) Predictors of Breast-Feeding in a Developing Country: Results of a Prospective Cohort Study. Public Health Nutr., 11, 1350-1356. http://dx.doi.org/10.1017/S1368980008003005

[13] Musaiger, A.O. and Abdulkhalek, N. (2000) Breastfeeding and Weaning Practices in Bahrain: The Role of Mothers' Education. Nutrition and Health, 14, 257-263. http://dx.doi.org/10.1177/026010600001400406

[14] Sharief, N.M., Margolis, S. and Townsend, T. (2001) Breastfeeding Patterns in Fujairah, United Arab Emirates. Journal of Tropical Pediatrics, 47, 304-306. http://dx.doi.org/10.1093/tropej/47.5.304

[15] Barros, F.C., Victora, C.G., Semer, T.C., TonioliFilho, S., Tomasi, E. and Weiderpass, E. (1995) Use of Pacifiers Is Associated with Decreased Breast-Feeding Duration. Pediatrics, 95, 497-499.

[16] Righard, L. and Alade, M.O. (1997) Breastfeeding and the Use of Pacifiers. Birth, 24, 116120. http://dx.doi.org/10.1111/j.1523-536X.1997.tb00351.x

[17] Mauch, C.E., Scott, J.A., Magarey, A.M. and Daniels, L.A. (2012) Predictors of and Reasons for Pacifier Use in First-Time Mothers: An Observational Study. BMC Pediatrics, 12, 7. http://dx.doi.org/10.1186/1471-2431-12-7

[18] Dashti, M., Scott, J.A., Edwards, C.A. and Al-Sughayer, M. (2010) Determinants of Breastfeeding Initiation among Mothers in Kuwait. International Breastfeeding Journal, $5,7$. http://dx.doi.org/10.1186/1746-4358-5-7

[19] Kambale, M.J. (2011) Social Determinants of Breastfeeding in Italy. African Health Sciences, 11, 508-517.

[20] Al-Sahab, B., Lanes, A., Feldman, M. and Tamim, H. (2010) Prevalence and Predictors of 6-Month Exclusive Breastfeeding among Canadian Women: A National Survey. BMC Pediatrics, 10, 20. http://dx.doi.org/10.1186/1471-2431-10-20

[21] Shiva, F. and Nasiri, M. (2003) A Study of Feeding Patterns in Young Infants. Journal of Tropical Pediatrics, 49, 89-92. http://dx.doi.org/10.1093/tropej/49.2.89

[22] Flood, J.L. (2013) Breastfeeding Patterns in the Rural Community of Hilo, Hawai'i: an Exploration of Existing Data Sets. Hawai $i$ Journal of Medicine \& Public Health, 72, 81-86.

[23] Liu, X., Zhang, J., Liu, Y., Li, Y. and Li, Z. (2012) The Association between Cesarean Deli- 
very on Maternal Request and Method of Newborn Feeding in China. PLoS ONE, 7, e37336. http://dx.doi.org/10.1371/journal.pone.0037336

[24] Kimani-Murage, E.W., Madise, N.J., Fotso, J.C., Kyobutungi, C., Mutua, M.K., et al. (2011) Patterns and Determinants of Breastfeeding and Complementary Feeding Practices in Urban Informal Settlements, Nairobi Kenya. BMC Public Health, 11, 396. http://dx.doi.org/10.1186/1471-2458-11-396

[25] Kent, J.C., Hepworth, A.R., Sherriff, J.L., Cox, D.B., Mitoulas, L.R. and Hartmann, P.E. (2013) Longitudinal Changes in Breastfeeding Patterns from 1 to 6 Months of Lactation. Breastfeeding Medicine, 8, 401-407. http://dx.doi.org/10.1089/bfm.2012.0141

[26] Sencan, I., Tekin, O. and Tatli, M.M. (2013) Factors Influencing Breastfeeding Duration: A Survey in a Turkish Population. European Journal of Pediatrics, 172, 1459-1466. http://dx.doi.org/10.1007/s00431-013-2066-8

[27] Perrine, C.G., Scanlon, K.S., Li, R., Odom, E. and Grummer-Strawn, L.M. (2012) Baby-Friendly Hospital Practices and Meeting Exclusive Breastfeeding Intention. Pediatrics, 130, 54-60. http://dx.doi.org/10.1542/peds.2011-3633

[28] Castilho, S.D. and Rocha, M.A. (2009) Pacifier Habit: History and Multidisciplinary View. J Pediatrics, 85, 480-459. http://dx.doi.org/10.2223/jped.1951

[29] Karabulut, E., Yalçin, S.S., Ozdemir-Geyik, P. and Karaağaoğlu, E. (2009) Effect of Pacifier Use on Exclusive and Any Breastfeeding: A Meta-Analysis. Turkish Journal of Pediatrics, 51, 35-43.

[30] Jaafar, S.H., Jahanfar, S., Angolkar, M. and Ho, J.J. (2012) Effect of Restricted Pacifier Use in Breastfeeding Term Infants for Increasing Duration of Breastfeeding. Cochrane Database of Systematic Reviews, Article ID: CD007202. http://dx.doi.org/10.1002/14651858.cd007202.pub3

[31] Jenik, A.G. and Vain, N. (2009) The Pacifier Debate. Early Human Development, 85, S89S91. http://dx.doi.org/10.1016/j.earlhumdev.2009.08.025

[32] Jenik, A.G., Vain, N., Gorestein, A.N. and Jacobi, N.E. (2009) Pacifier and Breastfeeding Trial Group. Does the Recommendation to Use a Pacifier Influence the Prevalence of Breastfeeding? Journal of Pediatrics, 155, 350-354.

http://dx.doi.org/10.1016/j.jpeds.2009.03.038

[33] Kramer, M.S., Barr, R.G., Dagenais, S., Yang, H., Jones, P., Ciofani, L., et al. (2001) Pacifier Use, Early Weaning, and Cry/Fuss Behavior: A Randomized Controlled Trial. JAMA, 286, 322-326. http://dx.doi.org/10.1001/jama.286.3.322

[34] Olang, B., Heidarzadeh, A., Strandvik, B. and Yngve, A. (2012) Reasons Given by Mothers for Discontinuing Breastfeeding in Iran. International Breastfeeding Journal, 7, 7. http://dx.doi.org/10.1186/1746-4358-7-7

[35] Ahmadpour-Kacho, M., Zahedpasha, Y. and Eshkevari, P. (2007) Comparison of the Rate of Exclusive Breast-Feeding between Pacifier Sucker and Non-Sucker Infants. Iranian Journal of Pediatrics, 17, 113-117.

[36] Shiva, F., Salemi, H. and Fakhte-Yavari, S. (2008) The Effect of Pacifier Use on BreastFeeding Duration. Pajouhesh Dar Pezeshki, 32, 261-265. (In Farsi)

[37] Gerd, A.T., Bergman, S., Dahlgren, J., Roswall, J. and Alm, B. (2012) Factors Associated with Discontinuation of Breastfeeding before 1 Month of Age. Acta Paediatrica, 101, 55-60. http://dx.doi.org/10.1111/j.1651-2227.2011.02405.x

[38] Roig, A.O., Martínez, M.R., García, J.C., Hoyos, S.P., Navidad, G.L., Alvarez, J.C., et al. (2010) Factors Associated to Breastfeeding Cessation before 6 Months. Revista LatinoAmericana de Enfermagem, 18, 373-380. http://dx.doi.org/10.1590/S0104-11692010000300012 
[39] Martins, E.J. and Giugliani, E.R. (2012) Which Women Breastfeed for 2 Years or More? Journal of Pediatrics, 88, 67-73. http://dx.doi.org/10.2223/JPED.2154

[40] Feldens, C.A., Vitolo, M.R., Rauber, F., Cruz, L.N. and Hilgert, J.B. (2012) Risk Factors for Discontinuing Breastfeeding in Southern Brazil: A Survival Analysis. Maternal and Child Health Journal, 16, 1257-1265. http://dx.doi.org/10.1007/s10995-011-0885-7

Submit or recommend next manuscript to SCIRP and we will provide best service for you:

Accepting pre-submission inquiries through Email, Facebook, LinkedIn, Twitter, etc. A wide selection of journals (inclusive of 9 subjects, more than 200 journals)

Providing 24-hour high-quality service User-friendly online submission system

Fair and swift peer-review system Efficient typesetting and proofreading procedure Display of the result of downloads and visits, as well as the number of cited articles Maximum dissemination of your research work

Submit your manuscript at: http://papersubmission.scirp.org/

Or contact ojog@scirp.org 